PLAYING BY DIFFERENT RULES: INDICATORS OF HAPPINESS ON PLAYGROUNDS

By

Michelle Rowland

B.A., Queen's University, Kingston, Ontario, 2016

\author{
A MRP \\ Presented to Ryerson University \\ in partial fulfillment of the requirements for the degree of \\ Master of Planning \\ in \\ Urban Development
}

Toronto, Ontario, Canada, 2018

(C) Michelle Rowland 2018 


\section{AUTHOR'S DECLARATION FOR ELECTRONIC SUBMISSION OF AN MRP}

I hereby declare that I am the sole author of this MRP. This is a true copy of the MRP, including any required final revisions.

I authorize Ryerson University to lend this MRP to other institutions or individuals for the purpose of scholarly research.

I further authorize Ryerson University to reproduce this MRP by photocopying or by other means, in total or in part, at the request of other institutions or individuals for the purpose of scholarly research.

I understand that my MRP may be made electronically available to the public 


\title{
PLAYING BY DIFFERENT RULES: INDICATORS OF HAPPINESS ON PLAYGROUNDS
}

\author{
(C) Michelle Rowland, 2018 \\ Master of Planning \\ in \\ Urban Development \\ Ryerson University
}

\begin{abstract}
As our cities continue to urbanize, opportunities for children's unstructured outdoor play are declining. Play is a right to children, and holds a critical role in children's lives. Creating opportunities for play during school hours produces significant physical and social health benefits. OPAL (Outdoor Play and Learning) is a registered community interest program originating in England transforming attitudes to play supervision, environment and provision within schools. In Toronto, Canada an OPAL pilot project is being implemented at six public elementary schools. Using data from this pilot, this study examines how differences in happiness while playing at schools vary across play conditions and duration. The study explores baseline data collected in Spring 2016 among 352 of 9-12-year-old children, attending grades 4 to 6 . Binomial logistic regression was performed for recess and lunch play showing the correlation between happiness and play duration. There are statistically significant relationships between happiness and play conditions.
\end{abstract}

Key words: outdoor play, unstructured, happiness, children, Toronto 


\section{Acknowledgements}

Thank you to my parents, without their love, support, and never ending cups of tea this would not have been possible. I am grateful to my friends, Spinsters, and classmates for listening to me talk about this all the time. Thank you to my supervisor Dr. Raktim Mitra for his guidance in my MRP. Thank you to Earth Day Canada for letting me be a part of their research project. Thank

you to Amanda O'Rourke, Executive Director of 880 Cities, for her expertise and shared passion for age-friendly cities. 


\section{Table of Contents}

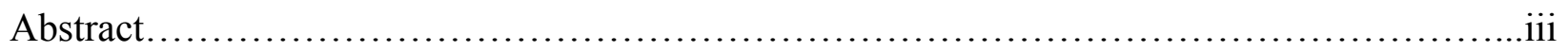

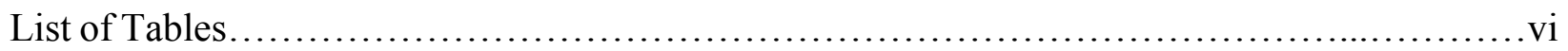

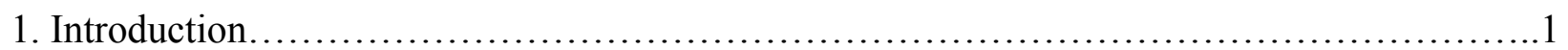

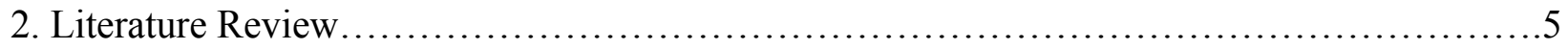

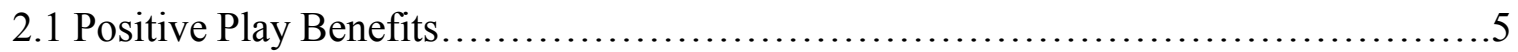

2.2 Socio-Demographics and its Impacts on Play .................................6

2.3 Risk and Challenge in Play......................................................

2.4 Changing Play Opportunities.................................................. 8

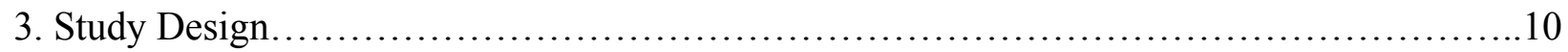

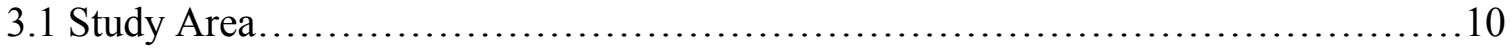

3.2 Data.............................................................................

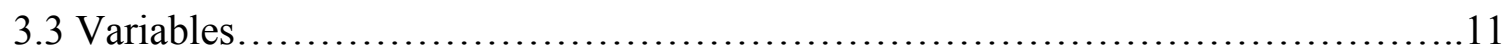

3.4 Binomial Logistic Regression................................................14

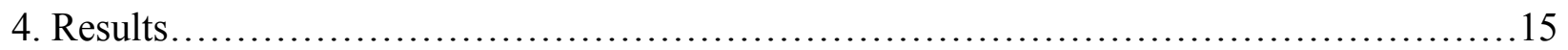

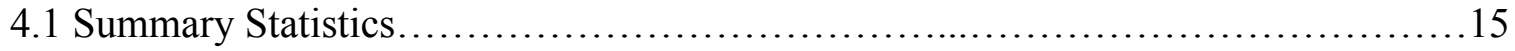

4.2 Correlates of Happiness During Outdoor Play ....................................17

4.3 Correlation between Happiness and Outdoor Play Time...............................19

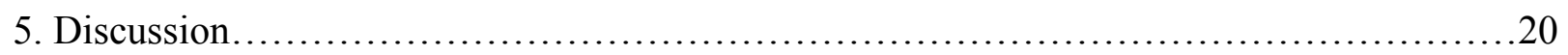

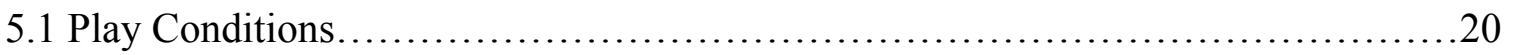

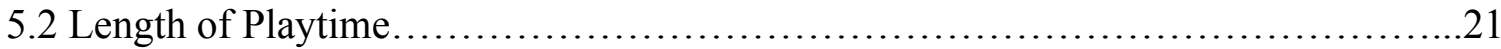

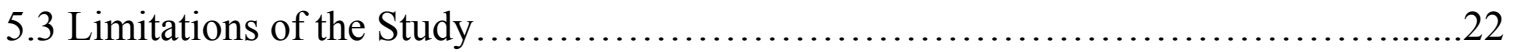

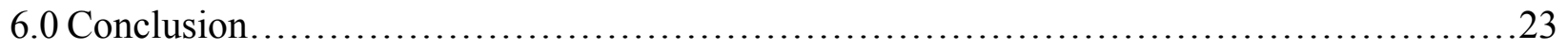

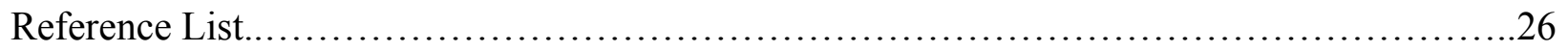




\section{List of Tables}

Table 3.1 - School Classification ................................................... 10

Table 3.2 - Variables explored for the play conditions.................................... 12

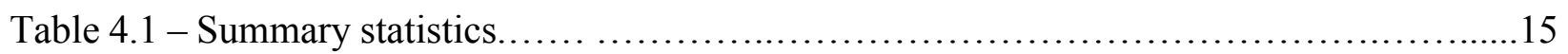

Table 4.2 - The association between happy outdoor play and play conditions at school...........18

Table 4.3 - How happiness relates to duration of outdoor play ............................. 19 


\section{Introduction}

Children today receive less support for free, spontaneous play than did previous generations, largely as a result of their increasingly fast paced lifestyle, changes in family structure, and increased attention to academics and enrichment activities (Goldstein, 2012; Lewis, 2017). Playing is an important element of children's health and wellbeing as it is different from structured activities like sport, art, and music (Davis, 2008; Lewis, 2017). While all of these activities can all have important contributions to a child's life, play is different because it allows children to be spontaneous, risky, and freely explore, lending to its importance for child development (Lewis, 2017; Little et al., 2011; Jarvis et al., 2014). Play contributes to the cognitive, physical, social, and emotional wellbeing of children (Goldstein, 2012; Lewis, 2017; Faulkner et al., 2015; Gleave and Cole-Hamilton, 2012; Gibson et al., 2017; Brez and Sheets, 2017; Staempfli, 2008; Barnett, 1990; Jarvis et al., 2014). Increasingly, as children feel 'hurried' through childhood by busy stressed adults, there has been a dwindling sense of wellness and subsequently happiness in North American society (Jarvis et al., 2014).

There are many articles from news outlets such as CNN and Telegraph UK about how happiness impacts children's play, particularly from a parental perspective, but there needs to be more substantive research to systematically examine the presence of the correlation of happiness and play (Sellgren, 2014; Acosta and Hutchison, 2017). Traditionally, research on children has relied on parental descriptions, but children deserve to have agency in the process (UusitaloMalmivaara, 2012). Research on happiness in cities centres around income, marriage, and satisfaction around one's job, which are all adult concerns, with little recognition for how children's happiness manifests (Leyden et al., 2011; Holder and Klassen, 2010). Happiness is being studied as a key outcome because it is a generalized indicator of subjective wellbeing, a broad concept of people's physical and mental health, and emotional wellbeing (UusitaloMalmivaara, 2012).

Opportunities for play continue to diminish with fewer play spaces, less freedom to roam outdoors, and children becoming increasingly busy (Goldstein, 2012; Lewis, 2017). The provision of space for play in the built environment takes many forms, including parks, playgrounds, public 
open spaces, streets, and especially school playgrounds (Brez and Sheets, 2017; Gibson et al., 2017). The richest play spaces are the most unplanned as how children will appropriate different spaces and features within their environment can be quite unpredictable by adults (Whitebread, 2012; Staempfli, 2008). The most successful urban play environments are set up so that children can adapt and build their own spaces, creating a freedom of choice, such as loose parts play (Staempfli, 2008; Whitebread, 2012; Gibson et al., 2017). In practice, however, over-engineered "safe" playgrounds across North America may have led to a decline in the quality and quantity of children's play.

Increasingly Canadian children are becoming more inactive with only $9 \%$ of Canadian kids getting the 60 minutes of heart-pumping physical activity they need each day (Participaction, 2016). Approximately only $37 \%$ of 11 to 15 year olds play outdoors for at least 2 hours each day (Participaction, 2016). The lack of physical activity for children increases the potential for obesity, heart diseases, and other body-weight related adverse health conditions (Gleave and ColeHamilton, 2012; Gibson et al., 2017). Research studies show that physical activity is positively correlated with happiness and mental health (Holder et al., 2009; Richards et al., 2015). Children in Canada spend an about 919 hours of instruction in the primary school classroom each year (OECD, 2014). Children are spending a large proportion of their waking hours at school, therefore designated playtime, specifically recess and longer playtimes are important because of the opportunity this break offers for children to be physically active, to recharge and socialize (Pawloski et al., 2014; Haug et al., 2010; Gleave and Cole-Hamilton, 2012; Pellegrini and Holmes, 2006; Faulkner et al., 2015). However, questions of why children do not fulfil their allotted recess physical activity time are not well understood (Pawloski et al., 2014; Haug et al., 2010). Despite the amount of evidence indicating the positive benefits from play, finding time for play outside of school can be challenging (Gleave and Cole-Hamilton, 2012). In schools, there is designated recess and lunch play time, however even with this provided time, there are still some students who do not maximize their playtime (Mitra, 2018).

Interventions at schools implementing loose parts play during scheduled play time has reported improvements in self-esteem, confidence, and social inclusion, alongside happiness 
(Gibson et al., 2017). Because of the vast array of differences in children, playgrounds with optional activities from unstructured play and organized activities provide opportunities for all children (McNamara et al., 2015). The Outdoor Play and Learning Project (OPAL) is a registered community interest program originating in England that transforms attitudes to play environment, supervision, and play provision within school communities (Earth Day Canada, 2017). In Toronto, Canada an OPAL pilot project is currently being adapted to the Ontario context to be implemented at six public elementary schools put on by Earth Day Canada (Earth Day Canada, 2017). Recognizing that play impacts healthy child development, the OPAL project's unstructured free play movement may contribute to enabling beneficial play conditions. The Earth Day Canada programming is influenced by OPAL principles, focusing on the quality of play provision, supervision, and risk management (Earth Day Canada, 2017). It is expected that improved play conditions on school grounds would create more engaging and exciting play experiences, producing greater physical, social, mental health benefits, and happiness for children. In this paper, I am examining happiness as an indicator of wellbeing, and happiness has previously been identified as a broad indicator of children's subjective wellbeing (Koch, 2017; Mitra et al., 2018).

Within this context, this major research paper (MRP) contributes by improving insights into the intersection between happiness during outdoor play, and aspects of play conditions in Toronto's public elementary schools. More specifically, using data collected from students in grades 4, 5 and 6, I have explored the statistical relationship between play conditions at school, and happiness while playing. Through regression analysis, I have also explored if happiness (while playing outdoors) varies across sociodemographic groups and in different urban contexts. Lastly, I have examined if happiness and outdoor playtime are positively correlated. Through a better understanding of what positively impacts children's happiness, more targeted interventions of the play conditions can be made.

Based on the results from statistical analysis, this MRP will explore the implications of happiness and outdoor playtime on policy and knowledge. Identification of differences in happiness while playing outdoors at schools of varying spatial and neighbourhood household income levels is a social planning issue. It can be costly to change hard infrastructure or retrofit 
the structure of existing neighbourhoods (Villanueva et al., 2016). Cost-effective place-based interventions such as pop up parks and playgrounds can have impacts on reclaiming spaces for children to play outdoors (Villanueva et al., 2016). The City of Toronto is the largest city and is the most multicultural city in Canada (Statistics Canada, 2016). Building on that, the TDSB is the largest and one of the most diverse schools districts in Canada (TDSB, 2014). The strategic directions of the TDSB includes identifying disadvantage and intervening effectively, so this MRP will make recommendations to improve the play conditions (TDSB, 2014). The TDSB does not have a specific play policy neither does the Ministry of Education (TDSB, 2014; Ministry of Education, n.d.).

This paper will begin with a literature review of relevant studies and research into the correlations between outdoor play, happiness and socio-demographic factors (Chapter 2). Following this is a study design which discusses the data sources, the play conditions and sociodemographic factors that could determine happiness, and data analysis methods (Chapter 3 ). The paper then continues with results of the data analysis and a discussion of the results in relation to existing literature on the topic (Chapter 4). A conclusion will then discuss implications of this research (Chapter 5). 


\subsection{Literature Review}

This literature review summarizes the relevant themes and existing evidence in the field of children's health and wellbeing in relation to play, the benefits of outdoor unstructured risky play, and how outdoor play and happiness may be correlated. An extensive review of research, in the form of peer-reviewed journals and grey literature, such as government and non-profit reports that pertain to outdoor play, was conducted. Words searched through Ryerson Library Summon include: loose parts, equity, outdoor, play, children, happiness, subjective wellbeing, unstructured, school.

\subsection{Positive Play Benefits}

In recent decades, there has been a growing concern that children are spending less time outdoors and becoming more sedentary (McClain and Vandermaas-Peeler, 2016). Play deprivation contributes to reduced happiness, among other things such as increased social isolation (Tremblay et al., 2015). While happiness is discussed as an important outcome of outdoor play, it is mainly from news articles not through academic research (Sellgren, 2014; Acosta and Hutchison, 2017). The concept of happiness, usually replaced by wellbeing, is multi-dimensional, encompassing physical, emotional and social wellbeing and focusing on children's immediate as well as their future lives (Uusitalo-Malmivaara, 2012; Gleave and Cole-Hamilton, 2012). Literature has related happiness with subjective wellbeing (Koch, 2017; Warnick, 2009; Gibbons and Silva, 2010). While there is a lack of research into the determinants of children's happiness and wellbeing in school, a growing body of research suggests that happiness and enjoyment in childhood are correlated with economic and emotional wellbeing later in life (Gibbons and Silva, 2010).

Physical activity during childhood and adolescence provides many short and long term health benefits such as building strong bones, muscle strength, and lung capacity (Brockman et al., 2009; Gleave and Cole-Hamilton, 2012). Research has consistently linked increased physical activity to not only physical health but also mental wellbeing (Gibson et al., 2017). Happiness is found to be linked to social relationships and social skills (Leyden et al., 2011). Free play offers many benefits for children as they practice important skills such as communication, prosocial 
behaviour, sharing, problem solving, self-regulation, and negotiation (Brez and Sheets, 2017; Staempfli, 2008; Gleave and Cole-Hamilton, 2012). Children have been shown to acquire knowledge more easily through play than other forms of learning (Barnett, 1990). Results from the main national German household survey $(n=815)$ show that in the development of everyday skills, positive effects were found with children who like to go to the playground to play (Anand and Roope, 2016). Play is good for developing motor functioning because children can achieve fundamental movement skills through unstructured free play (Gleave and Cole-Hamilton, 2012). The benefits of play are contextualized in terms of their ability to positively impact a child's cognitive, social, and emotional state, while these are important, happiness is not usually situated as the key outcome of play research (Gibson et al., 2017).

\subsection{Socio-Demographics and its Impacts on Play}

Studies show that for children in families with a low socio-economic position and ethnic minority, outdoor play is more scarce and conflicting (Wijtzes et al., 2014). Socio-demographics can inform to which, how and where a child is allowed to play, and subsequently determining the outcomes of play—such as happiness (Wijtzes et al., 2014; Blatchford et al., 2003). There are many external factors which can impact happiness such as family income and societal environment (Schimmel, 2009). Inequalities can have a considerable detrimental effect on happiness, and foster a feeling of deprivation (Schimmel, 2009). Therefore, it is important to discuss socio-demographic factors of a child's life when discussing their happiness because external factors will impact an individual (Schimmel, 2009).

Gender differences are typical across types of play, with boys mainly engaging in rough and tumble play while girls can more frequently be observed in games requiring verbal facility, such as chanting and jumping rope (Blatchford et al., 2003). Studies have shown that playground area type, size, and fixed outdoor equipment, together with supervision and organized activities explained $59 \%$ of the variance for boys and $42 \%$ of the variance for girls observed outdoor physical activity (Haug et al., 2010). More integration of children of different genders and ethnicities is seen in hybrid games (Blatchford et al., 2003). In recognizing that children may experience varying levels of parental encouragement and play opportunity in their homes, play in schools plays a 
pivotal role in a child's life (Wijtzes et al., 2014). There is an understanding that children with a low socio-economic status are much less likely to be physically active (Brockman et al., 2009). Less parental encouragement towards play could be linked to perceptions of risk in outdoor play (Farmer et al., 2017; Allin et al., 2014). In recognizing that children may experience varying levels of parental encouragement and play opportunity in their homes, play in schools has an important role in children's health and wellbeing (Wijtzes et al., 2014). Previous studies have explored the relationship between parental support for outdoor play in the home and neighbourhood environments, not previously parental encouragement at the school play level (Wijtzes et al., 2014; Allin et al., 2014; McClain and Vandermaas-Peeler, 2016; Smoyer-Tomic et al., 2004).

\subsection{Risk and Challenge in Play}

The growing concern of 'risk aversion' is limiting the degree of risk that children can encounter, thus diminishing the quality of play provision (Farmer et al., 2017; Little et al., 2011). Risky play allows for children to experience new emotions, and challenge themselves, creating confidence, a key factor in happiness (Niehues et al., 2015; Leyden et al., 2011). Without positive risk taking, children lose that mechanism to foster the development of their happiness (Gibson et al., 2017; Little et al., 2011; Niehues et al., 2015). Risk is an inherent and necessary part of play, the duty of play providers is to offer risk taking opportunities, and without such opportunities, children's happiness is impaired (Ball et al., 2008). A study in an impoverished area in England showed that $40 \%$ of children $(n=1973)$ regularly visited and played in wastelands, building sites, underpasses, rivers, abandoned buildings and quarries because they perceived that they were not obtaining challenging risky play opportunities in more supervised environments such as schools (Brussoni et al., 2012).

Fear of risk has manifested into parents becoming over protective of their children in what is called the "bubble-wrap" generation where children are so protected that they miss out on opportunities to be competent and independent users of their space (Norodahl and Johannesson, 2015). Unfortunately, most playground design is driven more by safety than developmental benefits, offering little opportunity for risk and challenge (Little and Eager, 2010; Shackell et al., 2008). Children in an Australian study $(n=38)$ when provided with a choice, $74 \%$ of participants 
preferred to play on the more challenging playground equipment (Brussoni et al., 2012). Modern playgrounds are characterized by a collection of single purpose equipment which do not facilitate flexible unstructured free play (Brez and Sheets, 2017). A study in Vancouver documented preschool children's use of play equipment in 16 childcare centres finding that play equipment was used only $13 \%$ of the time and was used as intended only $3 \%$ of the time (Brussoni et al., 2012).

How teachers and parents inform children about risks in the outdoors is influenced by societal cultures, Scandinavia has less problems with risk taking than countries such as Australia and the USA (Norodahl and Johannesson, 2015; Little et al., 2011). As a result of risk being societal driven, and not many Canadian examples exist exploring risk in outdoor play, this research will fill a much-needed gap. Play supervision is impacted by parents' and teachers' perceptions of risk, this plays out on the playground by adults putting restrictions on what a child can and cannot do. Qualitative interviews with teachers in New Zealand have indicated fear about the prospect of a child being injured while in their care and the potential litigation which could ensue, and they dealt with these concerns by removing loose parts or reducing the number of children in crowded areas (Farmer et al., 2017). There is a difference in male and female teachers' perceptions of risk on the playground; in a survey in Australia with Attitudes Towards Risk questionnaire, out of a total of 136 questions, male teachers had double the mean scores of female teachers meaning males engage in greater risk-taking behavior than females (Little et al., 2011). While differences can exist for children in their play conditions, differences can also occur in play supervision (Little et al., 2011).

\subsection{Changing Play Opportunities}

In recognizing the benefits of play has on a child's happiness, children's play opportunities, especially in schools, still seem to be declining as the time and space for play has eroded (Lewis, 2017). As cities push toward rapid urbanization and higher densities it puts pressure on public spaces and it results in spaces not being child-friendly (Villanueva et al., 2016). A study in southern Ontario across kindergarten to grade 8 students found four major challenges that adversely affect recess: minimal supervision, lack of equipment, lack of activities, and social conflict (McNamara 
et al., 2015). News articles written by play advocates discuss how increasingly there seems to be less play spaces being created even though residential real estate is still being created (Crone, 2010). Studies have shown that children living closer to playgrounds in nearby parks were more likely to be healthier, more active and playful, than children living further from parks and spaces (Potwarka et al., 2008). This shows the important role that school plays for children because if they do not live near parks this may be the only chance they are able to play outdoors each day.

The City of Toronto's recent study Growing Up: Planning for Children in New Vertical Communities guidelines provide an important tool to understand children's experiences in the City of Toronto (City of Toronto, 2017). Toronto is recognized as a "city within a park", the average distance between most homes and a nearby park space is only about $500 \mathrm{~m}$, but this does not speak to the quality of the place to play, only the availability (City of Toronto, 2013; Smoyer-Tomic et al., 2004). The City of Toronto is beginning to recognize the need for child-specific play spaces in downtown areas and high-rise communities, considering the needs of children and youth in city life (City of Toronto, 2017). While the City of Toronto has created these urban design guidelines to facilitate a child-friendly city, there is no mention of happiness in the policy (City of Toronto, 2017).

In summary, much research into children's play experiences focuses on healthy child development and physical activity levels (Tremblay et al., 2006; Richards et al., 2015). In comparison, little research focuses on the correlates of happiness or subjective wellbeing during outdoor play and sociodemographic factors. There are very few Canadian examples, with some examples from the United States of America, the United Kingdom, and Scandinavia, chosen for their similar climates. Having Canadian examples is important because how Canadians interact with the natural environment differs from other countries, in that Canadians can have limited access to outdoor space in the winter. From a methodological perspective, much of the research done is done with adults, such as teachers and parents, using a qualitative interview approach with less emphasis on a quantitative survey approach with the students themselves, and as a result there is a gap in the literature on reliable self-report measures to examine children's school play and happiness (Gibson et al., 2017; Hyndman et al., 2013). 


\subsection{Study Design}

This chapter will discuss the study area for this study, data sources and the methods that were used to perform the statistical analysis.

\subsection{Study Area}

Data from this study came from the Outdoor Play and Learning (OPAL) project put on by Earth Day Canada. The study area is the City of Toronto, Canada where the six public elementary schools received pilot OPAL programming. The city features a diverse range of children across age, gender, immigration statuses, and household incomes which helps to create a well-rounded diversity of children's outdoor play at school (Statistics Canada, 2016).

Schools were selected based on suggestions from the TDSB, but represent diversity with regard to their geographic location within the City of Toronto. The schools were further classified by neighbourhood income. This was calculated by seeing whether the neighbourhoods the schools were in had an average household income under or over the city median household income of $\$ 58$, 381 (Statistics Canada, 2016).

Table 3.1 - School Classification

\begin{tabular}{lllll}
\hline Classification & Urban or Suburban & Income & No. of Students & Grades \\
\hline School A & Urban & High & 88 & 4,5 \\
\hline School B & Urban & High & 28 & $4,5,6$ \\
\hline School C & Urban & High & 46 & $4,5,6$ \\
\hline School D & Suburban & Low & 57 & 4,5 \\
\hline School E & Suburban & & & $4,5,6$ \\
\hline School F & Urban & High & 113 & 4 \\
\hline
\end{tabular}




\subsection{Data}

Earth Day Canada has been working closely with each of the six school communities to develop an outdoor play implementation plan with OPAL principles (Mitra et al., 2018). The OPAL research project wanted to (1) improve their understanding of the benefits of such programming in enhancing children's play quality and wellbeing, and (2) provide insights that would improve larger scale program delivery at other Canadian school communities (Mitra et al., 2018). A longitudinal evaluation of the OPAL pilot was conducted across two years using a mixed methods approach with the collection of quantitative research, through surveys with students, and qualitative research, conducting interviews with teachers (Mitra et al., 2018). The survey included questions focusing on children's experiences with outdoor play conditions at school, including adult supervision, play material, safety and excitement (Mitra et al., 2018). Students recorded the amount of time they played at school before school hours, during recess, during lunch playtime, and after school. During the Spring of 2016 baseline data collection began with a total of 352 surveys collected. Baseline data collection was done at Alexmuir Junior Public School, Blake Street Public School, Chester Elementary School, Crescent Town Elementary School, Elmlea Junior School, and Lord Lansdowne Junior and Senior Public School (Mitra et al., 2018). Follow up surveys were conducted in the Fall of 2017, with Chester Elementary School, Crescent Town Elementary School and Lord Lansdowne Junior and Senior Public School, and will likely continue in 2018 (Mitra et al., 2018). Ethics approval for this survey was obtained from the Research Ethics Board at Ryerson University.

\subsection{Variables}

The primary focus of this research is to explore outdoor play at school, and examine the correlation between happiness and play conditions at school grounds. The key indicators of happiness were selected based on existing research that has characterized these as being impactful of a child's play experiences (Table 3.2). The Earth Day Canada interventions seek to target three key elements: play supervision, play provision, and risk management (Earth Day Canada, 2017). 
Parental encouragement was chosen as a play condition variable because parents have an impact on how a child plays, particularly their play in the neighbourhood, but parental impacts on school play are not well understood (Farmer et al., 2017; Allin et al., 2014). We are always allowed to play outside on our own or with friends with no adults with us was chosen as a play condition variable because it speaks to the play supervision provided in the school environment. This variable helps to clarify the independence children are afforded from adults in their lives. I think the adults at our play times help us have a really great play time was chosen as a play condition variable because play supervision is meant to help children have a great time, not hinder play opportunities. We get to play in the schoolyard at every free time all year, through all seasons, is a play condition variable because the Earth Day Canada program seeks to improve the quality of the play environment by giving children better access to play (Earth Day Canada, 2017). All weather play increases children's resilience, because they are not excessively sheltered from challenging situations which provide opportunities to develop coping skills (McArdle et al., 2013). There are plenty of things around for me to play with if I want to make up a game or build something was chosen as a play condition variable because it is central to OPAL's intervention by improving the play equipment by adding loose parts such as tires, wooden spools, pool noodles, tarps, and more to the playground to stimulate play (Earth Day Canada, 2017). My outdoor play time is generally very exciting was chosen as a play variable because play environments with lots to do and lots going on encourage more engaging play (Gibson et al., 2017). Play environments in which children feel safe in the schoolyard and do not have to worry about other kids are beneficial because playground safety is an indicator for increased physical activity for children (ArroyoJohnson et al., 2016).

Table 3.2 Variables explored for the play conditions

Play Conditions

Happiness

Gender

\section{Description}

How happy a child is when playing outdoors while at school (1 if a child was happy or very happy, 0 otherwise.

Gender of a child ( 1 if a girl, 0 otherwise) 


\begin{tabular}{|c|c|}
\hline Age & Age of a child (9-12 years) \\
\hline School & $\begin{array}{l}1=\text { Suburban Low Income, } 2=\text { Suburban High Income, } 3=\text { Urban High } \\
\text { Income, } 4=\text { Urban Low Income }\end{array}$ \\
\hline Recess Play & $\begin{array}{l}\text { Time spent playing during recess }(1=\text { Played outside less than } 10 \mathrm{~min}, 2= \\
\text { played more than } 10 \mathrm{~min} \text { or as long as allowed })\end{array}$ \\
\hline Lunch Play & $\begin{array}{l}\text { Time spent playing during lunch play }(1=\text { Played outside less than } 10 \mathrm{~min}, 2 \\
=\text { played more than } 10 \mathrm{~min} \text { or as long as allowed })\end{array}$ \\
\hline Parental Encouragement & $\begin{array}{l}\text { Whether children felt encouraged by their parents to play outdoors }(1= \\
\text { always, } 2=\text { sometimes, and } 3=\text { never })\end{array}$ \\
\hline $\begin{array}{l}\text { We are always allowed to play } \\
\text { outside on our own or with friends } \\
\text { with no adults with us }\end{array}$ & $\begin{array}{l}\text { If children are allowed to play outside on their own or with friends with no } \\
\text { adults ( } 1=\text { always and sometimes, } 2=\text { never })\end{array}$ \\
\hline $\begin{array}{l}\text { I think the adults at our play times } \\
\text { help us have a really great play } \\
\text { time. }\end{array}$ & Adults are helpful at play time ( $1=$ always and sometimes, $2=$ never $)$ \\
\hline $\begin{array}{l}\text { We get to play in the schoolyard at } \\
\text { every free time all year. }\end{array}$ & Playing outdoors during all seasons ( 1 = always, $2=$ sometimes and never $)$ \\
\hline $\begin{array}{l}\text { There are plenty of things around } \\
\text { for me to play with if I want to } \\
\text { make up a game or build } \\
\text { something. }\end{array}$ & $\begin{array}{l}\text { Amount of things to play with on the playground }(1=\text { always and sometimes, } \\
2=\text { never. }\end{array}$ \\
\hline $\begin{array}{l}\text { My outdoor play time is generally } \\
\text { very exciting }\end{array}$ & $\begin{array}{l}\text { Whether a child perceives their outdoor playtime to be exciting }(1=\text { always, } \\
2=\text { sometimes and never })\end{array}$ \\
\hline $\begin{array}{l}\text { Ifeel safe in the schoolyard and } \\
\text { do not have to worry about other } \\
\text { kids. }\end{array}$ & Feeling safe in the schoolyard ( $1=$ always, 2 = sometimes and never) \\
\hline
\end{tabular}




\subsection{Binomial Logistic Regression}

Statistical analyses of the results were conducted using the IBM SPSS Statistics program. Binomial logistic regression was used to determine statistically significant associations. Binomial logistic regression of happiness during outdoor play at school (very happy/happy versus not) was estimated, with all the indicators of the play condition in schools as independent variables. Students' socio-demographic characteristics and school types were included in the analysis as "control" variables.

Multi-variate binomial logistic regressions explored the likelihood of reporting happiness during outdoor play, in response to various potential influences. Two types of models were estimated: (1) 7 partially adjusted models, where each play condition was assessed at a time, controlling for variations in a child's age, gender and school type, and (2) 1 fully adjusted model, which represent the fully multivariate analysis that included socio-demographic variables, school types and all play condition-related variables. In addition, two logistic regression models were estimated for lunch time and recess-period outdoor play controlling for gender, age and school.

In a binomial logistic regression, the coefficient $\beta$ determines the size and direction of the relationship between an independent variable, and the logit of an outcome variable (Peng et al., 2002). In this paper, the results are reported in terms of the exponent of $\beta$, or the Odds Ratio (OR). In the context of my analysis, the OR demonstrates the odds of being happy while playing outside, in relation to a one-unit change in one of the play conditions at school, when all other variations are taken into account. 


\subsection{Results}

The study explores data on outdoor play that was collected from 352 children, attending 6 public elementary schools in Toronto. A summary of the socio-demographic characteristics of the sample as well as play conditions at schools is presented in Table 4.1. A binary logistic regression approach, results of which are summarised in Table 4.2, was adopted to explore statistical association between happiness, socio-demographic characteristics, and outdoor play conditions at school. Results from the relationship between length of time spent playing, ie. recess and lunch play, and happiness was analyzed with binomial logistic regressions, and the results are summarised in Table 4.3.

\subsection{Summary Statistics}

Table 4.1 shows the frequency distribution of each variable, highlighting the typical demographic makeup of the students who participated in the survey. Of the students, $78.8 \%$ are happy and $18.1 \%$ are not happy when playing outdoors at their schools.

Table 4.1 - Summary statistics

\begin{tabular}{|c|c|c|}
\hline Demographic Indicators & $n$ & $\%$ \\
\hline Happiness & 348 & \\
\hline Happy & & 78.8 \\
\hline Not Happy & & 18.1 \\
\hline Age & 352 & \\
\hline 9 years old & & 26.5 \\
\hline 10 years old & & 35.7 \\
\hline 11 years old & & 27.6 \\
\hline 12 years old & & 8.4 \\
\hline Gender & 352 & \\
\hline Girl & & 54.3 \\
\hline Boy & & 43.7 \\
\hline School & 352 & \\
\hline
\end{tabular}


Suburban Low Income

Suburban High Income

Urban High Income

Urban Low Income

Recess Play

Did not play or less than 10 min of play

More than $10 \mathrm{~min}$ in play or as long as recess

Lunch Play

Did not play or less than 10min of play

More than $10 \mathrm{~min}$ in play or as long as lunch

Parental Encouragement

Always

Sometimes

Never

We are always allowed to play outside on our own or with friends with no adults

Always \& Sometimes

Never

I think the adults at our play times help us have a really great play time

Always \& Sometimes

Never

We get to play in the schoolyard at every free time all year.

\section{Always \\ Sometimes \& Never}

There are plenty of things around for me to play with

\section{Always \& Sometimes}

Never

My outdoor play time is generally very exciting

Always
15.6

31.5

45.1

5.6

352

14.5

85.5

352

29.8

70.2

352

72.7

19.8

5.6

347

81.1

15.6

344

81.9

13.9

348

44.6

52.4

344

88.0

7.8

345

45.7 
Sometimes \& Never

I feel safe in the schoolyard and do not have to worry about other kids

Always

Sometimes \& Never
50.4

347

51.8

44.8

The distribution of gender in this research is $54.3 \%$ female and $44.6 \%$ male (Table 4.1 ). The distribution of males versus females in the research is not representative of the Toronto aged population 10-14 of $48.9 \%$ females (Statistics Canada, 2016).

Generally, children reported somewhat positive experiences with their play conditions. From the descriptive analyses, about half of the children generally feel supported in their play experience and feel their play experience to be exciting, safe, multi-seasonal, with helpful adults, and things to play with. While $74.1 \%$ of children feel their parents always encourage them to play, $15.9 \%$ of children always have to play outside with adults.

\subsection{Correlates of Happiness During Outdoor Play}

All binomial logistic regression models included gender, age and school type as control variables. None of these variables showed statistical association with happiness, and as such, those results are not shown here. The model fit (Cox \& Snell R Square) for the fully adjusted model was 0.198 which shows an acceptable model fit.

The results of the partially adjusted models (Table 4.2) indicate that most of the play condition related factors examined in our study were important in increasing the odds of a child's happiness while playing outdoors. However, "there are plenty of things around for me to play with" and "my outdoor playtime is generally very exciting" were the two variables that had the largest ORs. In the fully adjusted model, these were the only two significant results that we observed "there are plenty of things around for me to play with" OR 3.494 and "my outdoor playtime is generally very exciting" OR 10.574. The results indicate that when all other conditions 
are at their average level (i.e., set constant at their "reference" value), the most important aspects to improve are "there are plenty of things around for me to play with" and "my outdoor playtime is generally very exciting" because they will make a positive impact on happiness.

Table 4.2 The association between happy outdoor play and play conditions at school

\begin{tabular}{|c|c|c|c|c|}
\hline \multirow{3}{*}{$\begin{array}{c}\text { Key Indicators } \\
\text { Parental Encouragement }\end{array}$} & \multicolumn{2}{|c|}{ Partially Adjusted Model* } & \multicolumn{2}{|c|}{ Fully Adjusted Model** } \\
\hline & OR & $95 \% \mathrm{CI}$ & OR & $95 \% \mathrm{CI}$ \\
\hline & 2.176 & $1.413-3.349$ & 1.036 & $(.590-1.818)$ \\
\hline $\begin{array}{l}\text { We are always allowed } \\
\text { to play outside on our } \\
\text { own or with friends with } \\
\text { no adults with us }\end{array}$ & 2.133 & $1.068-4.260$ & 1.345 & $(.605-2.990)$ \\
\hline $\begin{array}{l}\text { I think the adults at our } \\
\text { play times help us have a } \\
\text { really great play time }\end{array}$ & 2.663 & $1.313-5.399$ & 1.314 & $(.570-3.025)$ \\
\hline $\begin{array}{l}\text { We get to play in the } \\
\text { schoolyard at every free } \\
\text { time all year }\end{array}$ & 1.000 & $.573-1.745$ & .819 & $(.429-1.561)$ \\
\hline $\begin{array}{l}\text { There are plenty of } \\
\text { things around for me to } \\
\text { play with if I want to } \\
\text { make up a game or build } \\
\text { something }\end{array}$ & 6.800 & 2.948-15.684 & 3.494 & $(1.287-9.483)$ \\
\hline $\begin{array}{l}\text { My outdoor play time is } \\
\text { generally very exciting }\end{array}$ & 13.703 & $5.539-33.900$ & 10.574 & $(4.088-27.349)$ \\
\hline $\begin{array}{l}\text { I feel safe in the } \\
\text { schoolyard and do not } \\
\text { have to worry about } \\
\text { other kids }\end{array}$ & 1.829 & $1.031-3.244$ & 1.139 & $(.587-2.210)$ \\
\hline
\end{tabular}

Notes: Odds Ratios that are bold are significant at $\alpha=0.05$.

*Models were adjusted for variations in a child's age, gender and school type.

** Models were adjusted for variations in a child's age, gender, school type and other play conditions included in the model. 


\subsection{Correlation between Happiness and Outdoor Play Time}

Through the binomial logistic regression models, the relationship between the level of happiness and the duration of both recess and lunch time play were examined. The results in Table 4.3 show that happiness is statistically associated with both recess and lunch time play. This is an extremely important observation. While the previous models in Table 4.2 shows the factors which can impact happiness emerging from outdoor play, the model in Table 4.3 shows a correlation between happiness and duration of play. Confirmation of the specific play conditions and duration of play which are correlated with happiness shows the importance of play in a child's school experience. This creates an onus on those working in schools and with children to improve play quality for children.

Table 4.3 The correlation between happiness and duration of outdoor play at school.

\begin{tabular}{|l|l|l|l|l|l|}
\hline \multicolumn{1}{|c|}{ Key Indicators } & Coefficient & $\begin{array}{c}\text { Standard } \\
\text { Error }\end{array}$ & Odds Ratio & $\begin{array}{c}\text { 95\% CI of } \\
\text { OR }\end{array}$ & p-value \\
\hline $\begin{array}{l}\text { Model 1: Recess Play } \\
\text { duration } \\
\text { Happy (ref: Not Happy) }\end{array}$ & $\mathbf{- 1 . 2 2 8}$ & .358 & .293 & $(.145-.590)$ & .001 \\
\hline $\begin{array}{l}\text { Model 2: Lunch Play } \\
\text { duration }\end{array}$ & $\begin{array}{l}\text { Happy (ref: Not Happy) } \\
\text { Hapre }\end{array}$ & $\mathbf{- . 7 8 8}$ & .455 & $(.252-.822)$ & .009 \\
\hline
\end{tabular}

Notes: Models were adjusted for variations in a child's age, gender and school type. 


\subsection{Discussion}

This chapter will discuss the results of the regressions and their implications. Research results will be discussed with regard to recent scholarly discourse. Areas of difficulty in the study will be addressed as well. This study sought to better understand and contribute to the literature on children's outdoor play experiences. The primary hypothesis was that children's happiness can be enhanced by improved outdoor play conditions. The results of the study support this hypothesis and indicate play conditions may significantly impact children's outdoor play experiences, measured here in terms of their likelihood of being happy while playing. There is little research on children's happiness and outdoor play at schools in the Canadian context so this will be a new contribution to the literature on this topic.

\subsection{Play Conditions}

The results of this analysis show correlates which may have been anticipated and some which were not anticipated. When adjusting for age, gender and school type, parental encouragement was seen to be statistically significant in the partially adjusted model. Children who were encouraged by their parents to play outside had 2.18 times higher odds of being happy than children who were not encouraged by their parents to play outside. This result was not statistically significant in the fully adjusted model, which is surprising because literature suggests that parental encouragement does have an impact on play, especially with risk and safety concerns (Norodahl and Johannesson, 2015; Farmer et al., 2017; Little et al., 2011). It is possible that parental encouragement is more impactful of play in the home and neighbourhoods as opposed to play in the school environment (Wijtzes et al., 2014; Allin et al., 2014).

Of the play condition variables, "there are plenty of things around for me to play with" and "my outdoor playtime is generally very exciting" came out as significantly associated with happiness in both the partially and fully adjusted models. While "we get to play in the schoolyard at every free time all year" came out as insignificant in both the partially and fully adjusted models. Children who think they have things to play with have 6.8 times the odds (in the partially adjusted model) of being happy while playing outside than those who do not think they have lots of things 
to play with. This echoes a lot of the research done surrounding loose parts play, where children have a more robust play experience when they have availability of things to play with on the playground (Gibson et al., 2017). Children who perceive their play time to be exciting have 13.7 times the odds (in the partially adjusted model) of being happy while playing outside than those who do not think they have an exciting play time. Being that things to play with and excitement level came out as being statistically significant, it shows that OPAL's intervention of adding loose parts for more things to play with on the playground could have an impact on excitement levels. Being that things to play with and excitement level came out as being statistically significant, it shows importance of an intervention focusing on adding loose parts play, such as what is being implemented through the OPAL pilot project in Toronto, in enhancing the wellbeing of children. Things to play with and exciting play are the most impactful when every other play condition is average, so in order to impact happiness the most for children through changing the play conditions those should be the starting point. Adding things to play with into playgrounds introduced movement materials and equipment to facilitate unstructured, child-led play (Gibson et al., 2017). Creating an exciting play environment, can be synonymous with a challenging play environment with diversity of the landscape, sparking imagination, and creating sensory experiences (Shackell et al., 2008; Staempfli, 2008). It is of interest to note that loose parts play, having things to play with on the playground, is seen to create excitement on playgrounds, so the two variables significant in the fully adjusted model have some overlap (Gibson et al., 2017).

\subsection{Length of Playtime}

This analysis indicates that happiness and time spent playing are positively correlated. Research has linked increased physical activity to both physical health and mental wellbeing (Gibson et al., 2017). Children who are deprived of play opportunities experience negative impacts such as reduced happiness (Tremblay et al., 2015). As a result of happiness and recess/lunch time play being statistically significant, it shows the importance that time to play has for children in schools. Children who spent more than $10 \mathrm{~min}$ or as long as recess playing outside were likely engaging in play that was active. While children who played more than 10 minutes or as long as they could, were the larger proportion (recess $85.5 \%$ and lunch $70.2 \%$ ). The amount of children playing less than $10 \mathrm{~min}$ during lunch, which is a longer time period than recess is quite large at 
$29.2 \%$ which should be drastically improved seeing as this research shows that happiness and play duration are statistically significant.

The primary focus of this study was to examine happiness as a simplistic indicator of a child's subjective wellbeing. The results from this regression confirm that happiness is also related to increased interests and engagement in play, therefore, making kids happy has implications for improved physical health as well. A child who was happy while playing was $30 \%$ more likely to play longer during recess. This result was statistically significant. A child who was happy while playing was $45 \%$ more likely to play longer during lunch playtime. This result was statistically significant. For both recess and lunch play, happiness emerged as a significant variable. Research

shows that children view their outdoor play time at schools as one of the only times where they are able to freely express themselves (Holmes, 2012). This data supports the findings that outdoor play time at schools is correlated with happiness (Gibson et al., 2017; Witjtzes et al., 2014). The field of happiness impacts on health is growing, so these findings are important as research has correlated physical activity with many benefits with reducing depression and anxiety (Zhang and Chen, 2018). While this research only focused on duration of play, there are also factors such as intensity of physical activity during play to consider (Zhang and Chen, 2018).

\subsection{Limitations of the Study}

Schools chosen for the study were chosen by the TDSB. While they generally represented the environmental and socio-economic diversity of Toronto, a systematic sampling was not possible. The OPAL pilot project is being implemented at only 6 public elementary schools in Toronto. As a result, the sample size for this analysis was only moderate, which might have affected the statistical robustness of the results. Also since the data was only collected on one day to capture a typical day for a child, it might be more beneficial to collect data over the period of a few days to collect more of a holistic picture of the child's play experiences. 


\subsection{Conclusion}

This study's purpose was to conduct an exploratory analysis of children's outdoor play experiences at schools across elementary school aged children in Toronto, Canada. Binomial logistic regression was used to identify correlations between play conditions (i.e., the quality of adult supervision, play environment and play equipment) and the odds of a child being happy while playing outdoors at school. The two consistent correlations with happiness across the partially and fully adjusted models were having access to things to play with and perceiving the playtime to be exciting. Children view recess as one of the few times when they were free to do things and to talk about them without adults controlling them (Holmes, 2012). The primary hypothesis was that children's happiness can be enhanced by improved outdoor play conditions. The results of the study support this hypothesis and indicate play conditions may significantly impact children's outdoor play experiences, measured in terms of their likelihood of being happy while playing. In the partially adjusted models, all but one of the variables emerged as statistically significant highlighting the various interventions that could be made to the play conditions. There is little research on children's happiness and outdoor play at schools in the Canadian context so this will be a new contribution to the literature on this topic.

The findings of this research support the importance of play conditions to improved children's happiness. The Earth Day Canada OPAL rollout is an impactful project because it focuses on improving play conditions through specific interventions such as adding loose parts to playgrounds and improving play supervision. As new and novel ideas emerge to improve children's play experiences, and subsequently happiness, further research should be conducted to more specifically identify targeted interventions in schools. While Earth Day Canada has been working in the Toronto school context, the full potential in the Canadian school context is yet to be explored. To fully understand the success and opportunities for the project, further surveys need to be carried out at all participating TDSB schools. Further studies may reveal stronger evidence in not only the relationship between improvements in play conditions and play-related outcomes, but also program implementation potentials and challenges. As only six schools were included in the analysis, further exploration of OPAL across the TDSB would create a more holistic image of the state of play in Toronto. 
While play mainly happens on playgrounds, play needs to increasingly be discussed at a policy level. Children view playing at recess akin to an unalienable right (Holmes, 2012). As planners and policy makers there is an onus to create policies which positively impact play. While the TDSB does not have a play policy, there are international precedents for creating play policies. The first government to legislate play was Wales in 2014, outlining in their policy the government's commitment to providing high quality of play opportunities for children to mitigate the negative impacts of poverty and to build social resilience (Wales, 2014). The Welsh government aims to direct decision making at all levels to consider the impacts of the policies to ensure meaningful opportunities for children (Wales, 2014). Having a play policy for across the whole TDSB would ensure a quality of play provision for all children. Ensuring a consistent positive level of play across the TDSB creates equitable access to play, and subsequently as this research shows, equitable access to happiness. Importantly, play policies make rules and guidelines clear for play supervision for adults. The Earth Day Canada project argues that play conditions are not enough to be changed, play supervision must be changed as well to ensure that adults are facilitating the best play possible for children (Earth Day Canada, 2017).

Although this MRP focuses on play in schools, play outside of schools can also positively contribute to children's happiness so play in public spaces needs to be considered. As the state of play continues to evolve into more loose parts, messy, unstructured play, there are implications of how OPAL style programming could be applied into other public spaces. As previously mentioned, Toronto is recognized as a "city within a park", the average distance between most homes and a nearby park space is only about $500 \mathrm{~m}$, but this does not speak to the quality of the place to play, only the availability (City of Toronto, 2013; Smoyer-Tomic et al., 2004). Implementing more messy, unstructured types of play into public spaces could bring about the same benefits as this type of play in schools, however the supervision piece would be different in public spaces.

In the field of urban planning, children are not the centre of many discussions, or even included. This MRP seeks to make contributions to urban planning by focusing on creating a more childfriendly city. By discussing happiness and play, this MRP seeks to bring to light the most critical part of a child's day, play. Urban planning wants to make people happy and healthy. Play does 
both of those things through being active and facilitating authentic experiences. It then begs the question, if planning was more centered on happiness, what could have changed in the development of our cities? The City of Toronto is working on initiatives such as Growing Up TO but this is focused on the built form and urban design. This MRP brings a new perspective to the field of urban planning, as most other similar research studies are published in Early Childhood Education, Education, Psychology or Kinesiology fields. There is not much research in the field of planning surrounding children, there are also not many Ryerson Master of Planning MRPs which discuss children, meaning this MRP helps to fill a void. 


\section{Reference List}

Acosta, Rina Mae., and Hutchison, Michele. (2017). They Raise the World's Happiest Children - So is it Time You Went Dutch? Telegraph UK. Retrieved from https://www.telegraph.co.uk/women/family/raise-worlds-happiest-children-time-went-dutch/

Allin, Linda., West, Amanda., and Curry, Stephanie. (2014). Mother and Child Constructions of Risk in Outdoor Play. Leisure Studies, 33(6), 644-657.

Anand, Paul., and Roope, Laurence. (2016). The Development and Happiness of Very Young Children. Social Choice and Welfare, 47(4), 825-851.

Arroyo-Johnson, Cassandra., Krista Woodward, Laurel Milam, Nicole Ackermann, Goldie Komaie, Melody S Goodman, and J. Aaron Hipp. (2016). Still Separate, Still Unequal: Social Determinants of Playground Safety and Proximity Disparities in St. Louis. Journal of Urban Health, 93(4).

Ball, David., Gill, Tim., and Spiegel, Bernard. (2008). Managing Risk in Play Provision: Implementation Guide. Play England.

Barnett, Lynn. (1990). Developmental Benefits of Play for Children. Journal of Leisure Research, 22(2), 138-153.

Blatchford, Peter., Baines, Ed., and Pellegrini, Anthony. (2003). The Social Context of School Playground Games: Sex and Ethnic Differences, and Changes over Time After Entry to Junior School. British Journal of Developmental Psychology, 21, 481-505.

Brez, Caitlin., and Sheets, Virgil. (2017). Classroom Benefits of Recess. Learning Environments Research, 3. 
Brockman, R., Jago, R., Fox, KR., Thompson, JL., Cartwright, K, and Page, AS. (2009). “Get Off the Sofa and Go and Play": Family and Socioeconomic Influences on the Physical Activity of 10-11-year-old Children. BMC Public Health, 21(9), 253.

Brussoni, Mariana., Gibbons, Rebecca., Gray, Casey., Ishikawa, Takuro., Sandseter, Ellen Beate Hansen., Bienenstock, Adam., Chabot, Guylaine., Fuselli, Pamela., Herrington, Susan., Janssen, Ian., Pickett, William., Power, Marlene., Stanger, Nick., Sampson, Margaret, and Tremblay, Mark S. (2015). What is the Relationship between Risky Outdoor Play and Health in Children? A Systematic Review. International Journal of Environmental Research and Public Health, 12(6), 6423-6454.

Brussoni, Mariana., Olsen, Lise., Pike, Ian., and Sleet, David. (2012). Risky Play and Children's Safety: Balancing Priorities for Optimal Child Development. International Journal of Environmental Research and Public Health, 9(9), 3134-3148.

City of Toronto. (2013). Parks Plan 2013-2017. Retrieved from https://www.toronto.ca/wpcontent/uploads/2017/08/9645-parks-plan-2013-17.pdf

Crone, Neil. (2010). With Each Subdivision Comes Less Places to Play. Northumberland News, Coburg Ontario.

Earth Day Canada. (2017). Outdoor Play and Learning Program for Schools. Retrieved from https://earthday.ca/earthplay/schoolplay/

Farmer, Victoria., Fitzgerald, Ruth., Williams, Sheila., Mann, Jim., Schofield, Grant., McPhee, Julia., and Taylor, Rachael. (2017). What did Schools Experience from Participating in a Randomised Controlled Study (PLAY) that Prioritized Risk and Challenge in Active Play for Children While at School? Journal of Adventure Education and Outdoor Learning, 17(3), 239-257. 
Faulkner, Guy., Hefferon, Katie., and Mutrie, Nanette. (2015). Putting Positive Psychology into Motion Through Physical Activity. (Eds). In Joseph, Steve., Positive Psychology in Practice: Promoting Human Flourishing in Work, Health, Education, and Everyday Life. New Jersey: John Wiley and Sons.

Gibbons, Stephen, and Silva, Olmo. (2010). School Quality, Child Wellbeing and Parent's Satisfaction. Economics of Education, 30, 312-331.

Gibson, Jenny., Cornell, Megan., and Gill, Tim. (2017). A Systematic Review of Research into the Impact of Loose Parts Play on Children's Cognitive, Social and Emotional Development. School Mental Health, 9(4), 295-309.

Gleave, Josie., and Cole-Hamilton, Issy. (2012). A Literature Review on the Effects of Lack of Play on Children's Lives. Play England, 1-32.

Growing Up: Planning for Children in New Vertical Communities. (2017). City of Toronto. Retrieved from http://www1.toronto.ca/wps/portal/contentonly?vgnextoid=35cf62e9d88c0510VgnVCM1 0000071d60f89RCRD

Haug, Ellen., Torsheim, Torbjørn., Sallis, James F., and Oddrun Samdal. (2010). The Characteristics of Outdoor School Environment Associated with Physical Activity. Health Education Research, 25(2), 248-256.

Holder, Mark D., and Klassen, Andrea. (2010). Temperament and Happiness in Children. Journal of Happiness Studies, 11, 419-439.

Holder, Mark D., Coleman, Benjamin., and Sehn, Zoe L. (2009). The Contribution of Active and Passive Leisure to Children's Well-being. Journal of Health Psychology, 14(3), 378-386. 
Holmes, Robyn. (2012). The Outdoor Recess Activities of Children at an Urban School. American, 4(3).

Hyndman, Brendon., Telford, Amanda., Finch, Caroline., Ullah, Shahid., and Benson, Amanda. (2013). The Development of the Lunchtime Enjoyment of Activity and Play Questionnaire. Journal of School Health, 83(4).

Israel, Solomon. (2016). Toronto Still 'Child Poverty Capital” of Canada, warns report. $C B C$ News. Retrieved from http://www.cbc.ca/news/canada/toronto/toronto-child-poverty-dividedcity-1.3849696

Jarvis, Pam., Newman, Stephen., and Swiniarski, Louise. (2014). On 'Becoming Social': The Importance of Collaborative Free Play in Childhood. International Journal of Play, 3(1), 53-68.

Koch, Anette Boye. (2017). Children's Perspectives on Happiness and Subjective Wellbeing in Preschool. Children \& Society, 32(1).

Little, Helen., and Eager, David. (2010). Risk, Challenge, and Safety: Implications for Play Quality and Playground Design. European Early Childhood Education Research Journal, 18(4), 497-513.

Little, Helen., Wyver, Shirley., and Gisbon, Frances. (2011). The Influence of Play Context and Adult Attitudes on Young Children's Physical Risk-Taking During Outdoor Play. European Early Childhood Education Research Journal, 19(1), 113-131.

Lewis, Patrick J. (2017). The Erosion of Play. International Journal of Play, 6(1), 10-23.

Leyden, Kevin., Goldberg, Abraham., Michelbach, Philip. (2011). Understanding the Pursuit of Happiness in Ten Major Cities. Urban Affairs Review, 47(6), 861-888. 
Llywodraeth Cymru Welsh Government. (2014). Wales - a Play Friendly Country. Retrieved from www.cmyru.gov.uk

Madsen, Kristine., Hicks, Katherine., and Thompson, Hannah. (2011). Physical Activity and Positive Youth Development: Impact of a School-Based Program. $J$ Sch Health, 81(8), 462-470.

McArdle, Karen., Harrison, Terri., and Harrison, Daniel. (2013). Does a Nurturing Approach that Uses an Outdoor Play Environment Build Resilience in Children from a Challenging Background? Journal of Adventure Education and Outdoor Learning, 13(3), 238-254.

McClain, Cara., and Vandermaas-Peeler, Maureen. (2016). Social Contexts of Development in Natural Outdoor Environments: Children's Motor Activities, Personal Challenges and Peer Interactions at the River and the Creek. Journal of Adventure Education and Outdoor Learning, 16(1), 31-48.

McNamara, Lauren., Vaantaja, Erin., Dunseith, Ashley., and Franklin, Nicole. (2015). Tales from the Playground: Transforming the Context of Recess Through Collaborative Action Research. International Journal of Play, 4(1), 49-68.

Ministry of Education. (n.d.). Program for Children. Ontario Ministry of Education. Retrieved from http://www.edu.gov.on.ca/earlyyears/program-for-children.html

Mitra, Raktim. (2018, January). Outdoor Play and Children's Wellbeing: Evaluating the Impacts of the OPAL Pilot Program. OPAL Conference. Earth Day Canada, Toronto.

Mitra, Raktim., Propa, Farzana, and Rowland, Michelle. (2018). Outdoor Play and Learning (OPAL) in School Communities: Results from the Pilot Programming in Toronto. Toronto, Earth Day Canada. 
Neighbourhood Profiles. (2016). City of Toronto. Retrieved from https://www.toronto.ca/citygovernment/data-research-maps/neighbourhoods-communities/neighbourhood-profiles/

Niehues, Anita Nelson., Bundy, Anita., Broom, Alex., and Tranter, Paul. (2015). Parents' Perceptions of Risk and the Influence on Children's Everyday Activities. Journal of Child and Family Studies. 24: 809-820.

Norðdahl, Kristín., and Jóhannesson, Ingólfur Ásgeir. (2015). Children’s Outdoor Environment in Icelandic Education Policy. Scandinavian Journal of Educational Research, 59(1), 1-23.

OECD. (2014), “Indicator D1: How much time do students spend in the classroom?”, in Education at a Glance 2014: OECD Indicators, OECD Publishing.

Pawloswki, Charlotte., Tjørnhøj-Thomsen, Tine., Schipperjin, Jasper., and Jens Troelsen. "Barriers for Recess Physical Activity: A Gender Specific Qualitative Focus Group Exploration. BMC Public Health, 14, 2014.

Pellegrini, AD. and Holmes, RM. (2006) The Role of Recess in Primary School. In Singer, D. G, Golinkoff, RM and Hirsh-Pasek, K. (Eds). Play = Learning: How Play Motivates and Enhances Children's Cognitive and Social-Emotional Growth. Oxford: Oxford University Press.

Peng, Chao-Ying Joanne., Lee, Kuk Lida., and Ingersoll, Gary M. (2002). An Introduction to Logistic Regression Analysis and Reporting. Journal of Education Research.

Potwarka, Luke R., Kaczynski, Andrew T., Flack, Andrea L. (2008). Places to Play: Association of Park Space and Facilities with Healthy Weight Status among Children. Journal of Community Health, 33(5), 344-3501.

Richards, Justin., Jiang, Xiaoxiao., Kelly, Paul., Chau, Josephine., Bauman, Adrian, and Ding, Ding. (2015). Don't Worry, Be Happy: Cross-Sectional Associations Between Physical Activity and Happiness in 15 European Countries. BMC Public Health, 15(53). 
Schimmel, Jorg. (2009). Development as Happiness: The Subjective Perception of Happiness and UNDP's Analysis of Poverty, Wealth, and Development. Journal of Happiness Studies, 10, 93-111.

Sellgren, Katherine. (2014). Play 'Boosts Children's Development and Happiness'. BBC. Retrieved from http://www.bbc.com/news/education-28658441

Shackell, Aileen., Butler, Nicola., Doyle, Phil., and Ball, David. (2008). Design for Play: A Guide to Creating Successful Play Spaces. Play England.

Smoyer-Tomic, Karen., and Hewko, Jared., and Hodgson, M. John. (2004). Spatial Accessibility and Equity of Playgrounds in Edmonton, Canada. The Canadian Geographer, 48(3), 287-302.

Staempfli, Marianne B. (2008). Reintroducing Adventure into Children's Outdoor Play Environments. Environment and Behaviour, 41(2), 268-280.

Statistics Canada. (2016). Canadian Census Data, 2016. Government of Canada. Retrieved from http://www.statcan.gc.ca/

Toronto District School Board. (2014). About Us. Retrieved from http://www.tdsb.on.ca

Tremblay, Mark., Bryan, Shirley., Perez, Claudio., Arden, Chris., and Katzmarayk, Peter. (2006) Physical Activity and Immigrant Status. Canadian Journal of Public Health, 97(4).

Tremblay, Mark., Gray, Casey., Babcock, Shawna., Barnes, Joel., Bradstreet, Christa Costas., Collyer, Cam., Herrington, Susan., Janson, Katherine., Janssen, Ian., Larouche, Richard., Pickett, William., Power, Marlene., Sandseter, Ellen Beate Hansen., Simon, Brenda., and Brussoni, Mariana. (2015). Position Statement on Active Outdoor Play. International Journal of Environmental Research and Public Health, 12, 5475-6505. 
Uusitalo-Malmivaara, Lotta. (2012). Global and School-Related Happiness in Finnish Children. Journal of Happiness Studies, 13, 601-619.

Villanueva, Karen., Badland, Hannah., Kvalsvig, Amanda., O'Connor, Meredith., Christian, Hayley., Woolcock, Geoffrey., Giles-Corti, Bilie., and Goldfeld, Sharon. (2016). Can the Neighborhood Built Environment Make a Difference in Children's Development? Building the Research Agenda to Create Evidence for Place-Based Children's Policy. Academic Pediatrics, 16(1), 10-19.

Warnick, Bryan R.. (2009). Dilemmas of Autonomy and Happiness: Harry Brighouse on Subjective Wellbeing in Education. Theory and Research in Education, 7(1), 89-111.

Whitebread, David. (2012). Importance of Play. Toy Industries of Europe.

Wijtzes, Anne., Jansen, Wilma., Bouthoorn, Selma., Pot, Niek., Hoffman, Albert., Jaddoe, Vincent., and Raat, Hein. (2014). Social Inequalities in Young Children's Sports Participation and Outdoor Play. International Journal of Behavioural Nutrition and Physical Activity, 11(155).

Zhang, Zhanjia and Chen, Weiyun. (2018). A Systematic Review of the Relationship Between Physical Activity and Happiness. Journal of Happiness Studies, 1-18. 